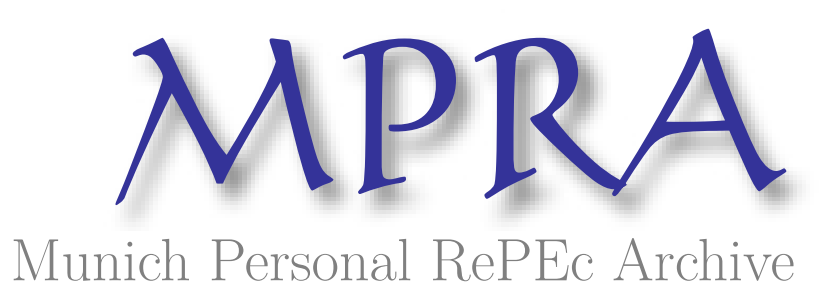

\title{
Fisherian Futures Market
}

Kim, Minseong

16 December 2015

Online at https://mpra.ub.uni-muenchen.de/68387/

MPRA Paper No. 68387, posted 16 Dec 2015 16:00 UTC 


\title{
Fisherian Futures Market
}

\author{
Minseong Kim
}

$2015 / 12 / 16$

\begin{abstract}
The very fact that utility maximization in real business cycle and New Keynesian models is intertemporal suggests the possibility of a Fisherian intertemporal futures market, which is not state-contingent. Ex-ante speaking, the addition of a futures market does not result in any difference, but the addition does make difference ex-post. Furthermore, New Keynesian models rely on nominal effects, and what would introduction of a Fisherian futures market mean for these models? This paper answers this question by presenting a model that features Fisherian intertemporal futures markets.
\end{abstract}

\section{Interpreting New Keynesian models}

Many DSGE models start from some utility function specified. Let us for now specify the utility maximization form for a representative household, assuming there is no capital in an economy, of following:

$$
V(C, N)=\max _{C_{t}, N_{t}} \sum_{t=0}^{\infty} \beta^{t}\left[\frac{C_{t}^{1-\sigma}}{1-\sigma}-\frac{N_{t}^{1+\chi}}{1+\chi}\right]
$$

under budget constraint:

$$
C_{t}+Q_{t} B_{t} \leq W_{t} N_{t}+B_{t-1}+\Pi_{t}
$$

where $C_{t}$ is consumption, $N_{t}$ is labor used in each period, $\beta$ is time preference, $P i_{t}$ is profit dividends earned and $B_{t}$ is quantity of one-time bond purchased that pays off $B_{t}$ at time $t+1$ with $Q_{t}$ representing price of bond of one quantity of bond $B_{t}$ at time $t$. $W_{t}$ is real wage received.

As with generally other DSGE models, this suggests foundation in ArrowDebreu models, where every commodity is a state-contingent claim.

One may however also postulate a futures market - where every futures claim is enforced. In this market at present time $t=0$, one pays for future $(t>0)$ delivery of $k$ quantity of some good at $t=0$ and is guaranteed to get exactly that $k$ quantity at some $t>0$. 
For a representative household, using a futures market brings equal ex-ante utility maximization, and from an expected utility theory perspective, there is no reason why a household would not use a futures market. The equivalence can be checked with the slightly different budget constraint:

$$
\sum_{t=0}^{\infty}\left[X_{t} C_{t}\right] \leq \sum_{t=0}^{\infty}\left[F_{t} W_{t} N_{t}+\Pi_{t}\right]
$$

The question then arises: how would introduction of nominal factors, such as price stickiness, into this class of models be justified? If there are costs to changing price or obtaining information, then an one-time search would provide benefits also. In practice, some firms perish, and type of goods changes - but the class of models being described here assume ergodicity. If ergodicity cannot be assumed that there is even no point of discussion here, as all models are going to be invalid. Fortunately, a half-answer actually comes from a simple observation.

Suppose every agent participates in a Fisherian futures market. Firms use Cobb-Douglas technology:

$$
Y_{t}(i)=A_{t}\left[N_{t}(i)\right]^{1-\alpha}
$$

where $i \in[0,1]$ refers to individual firm, and all firms share technology access $A_{t}$. If $A_{t}$ is stochastic, then shocks would disturb ex-ante expectations. If $A_{t}$ suffers from positive shock, then $Y_{t}$ would be greater than demanded $Y_{t}$. If $A_{t}$ suffers from negative shock, then $Y_{t}$ would be less than demanded $Y_{t}$.

There are two main directions to resolve this problem:

- Renegotiations are allowed.

- There are some agents that wish to purchase consumption goods at a spot market, while others prefer to plan ahead-of-time at futures markets.

In either case, some effects similar to price and wage stickiness can be introduced, even though all effects are rationally optimal.

\section{Fisherian Futures Market Model}

This section first deals with the latter item in the list from the previous section. In this economy, for goods dated for delivery at time $t=0, \theta$ of all household agents purchase the goods at $t=0, \theta^{2}$ of agents purchase rights for the goods at $t=-1$ (futures market), $\theta^{3}$ of agents purchase rights for the goods at $t=-2$ (futures market) and so on. To normalize properly,

$$
\sum_{t=-\infty}^{0} \theta^{-t+1}=\frac{\theta}{1-\theta}=1
$$

meaning $\theta=0.5$. The choice is completely arbitrary, and may be generalized for extensions. 
Assume that every agent shares the same utility form described in Equation 1. Let $N_{t}=N_{t, a}+N_{t, b}$, where $N_{t, a}$ refers to labor amount pre-determined in futures market. $Y_{t}=Y_{t, a}+Y_{t, b}=C_{t, a}+C_{t, b}$. The equilibrium condition for remaining people is:

$$
\left(d_{t} C_{t, b}\right)^{\sigma}\left(d_{t} N_{t, b}\right)^{\chi}=(1-\alpha) A_{t} N_{t}^{\alpha}
$$

where $d_{t}$ is the coefficient used to normalize $N_{t, b}$ and $Y_{t, b}$ for utility maximization calculation. $d$ is determined from the no-shock case:

$$
\left(d_{t} \theta \bar{Y}_{t}\right)^{\sigma}\left(d_{t} \theta \bar{N}_{t}\right)^{\chi}=(1-\alpha) \bar{A}_{t} \bar{N}_{t}^{\alpha}
$$

where $\bar{Y}_{t}, \bar{N}_{t}, \bar{A}_{t}$ refer to the no-technology-shock case.

Assume for convenience $\alpha=0$. That is, $Y_{t}=A_{t} N_{t}$. Then,

$$
d_{t}{ }^{\sigma+\chi} C_{t, b}{ }^{\sigma} N_{t, b}{ }^{\chi}=A_{t}
$$

Convert this into:

$$
d_{t}^{\sigma+\chi}\left(Y_{t}-C_{t, a}\right)^{\sigma}\left[\frac{Y_{t}-Y_{t, a}}{A_{t}}\right]^{\chi}=A_{t}
$$

Thus, $Y_{t}$ and $N_{t}$ are determined.

\section{Fisherian Futures Market with Passive Firms and Renegotiation Model}

Let us again think of the case where all of households, or the representative household participates completely in a Fisherian Futures market at some starting time $t=-k$ with $k>0$. The contracts are strictly enforced without any incurred monitoring costs, and no deviation can be possible, as assumed before. Assume as done before that no collateral is required.

As seen before, in case of negative technology shock, contracts cannot be followed by the representative firm. Let us for now assume that in case of any technology shock at present time $t=0$, both positive and negative, the representative firm can renegotiate wage and labor amount with the representative household at $t=0$ and only for $t=0$.

It is clear that the representative household, with its contracts mandating enforcement, would not agree to any agreement that provides less wage and more labor amount. Thus, the firm is forced to provide more wage and induce the household to work equivalently or more.

In case of negative technology shock, the firm produces less than what it needs to, and thus requires bidding up wage to produce remaining goods. The minimum wage demanded is:

$$
Y_{t, a}{ }^{\sigma}\left[\left(\frac{Y_{t, a}}{A_{t}}\right)^{1 /(1-\alpha)}\right]^{\chi}
$$


(Recall that there is only A-type agent here, and $Y_{t} t, a, A_{t}$ are given at present time $t=0$.)

The firm must provide at minimum this wage if any negative technology shock on $A_{t}$ occurs, and this is guaranteed to be greater than the previously negotiated wage at $t=-k$.

In case of positive technology, the firm produces more than what it needs to, and the firm may attempt generating more profit. But agents already spent all of their endowments due to the binding futures contract. Thus, the household must be given additional wage to consume surplus goods, and this in turn means producing additional goods. The wage is given in such a case by:

$$
(1-\alpha) A_{t} N_{t}^{-\alpha}=\left[A_{t} N_{t}^{1-\alpha}\right]^{\sigma} N_{t}^{\chi}
$$

Unlike the negative shock case, the equilibrium labor amount and wage is not determined by labor force. In both negative and positive shock cases, wage increases.

Let the solution of Equation 11 for labor $N_{t}$ be $\phi\left\{N_{t}\right\}$ and the solution of Equation 11 for output $Y_{t}$ as $\phi\left\{Y_{t}\right\}$.

This observation shows that $Y_{t, a}$ should not be equal to $C E\left(Y_{t}\right)=E_{t^{\prime}}\left[A_{t}\right] \gamma\left\{N_{t}\right\}$ where $\gamma\left\{N_{t}\right\}$ is the optimal $N_{t}$ assuming that no shock ever occurs after time $t^{\prime}$, the time of the Fisherian futures market. The other way of saying this is that $Y_{t, a}$ does not possess certainty equivalence. $Y_{t, a}$ is determined from the following equation:

$$
\begin{gathered}
G_{1}^{\prime}=\int_{0}^{\lambda} Y_{t, a} p\left(A_{t}\right) d A_{t} \\
G_{2}^{\prime}=\int_{\lambda}^{\infty} \phi\left\{Y_{t}\right\} p\left(A_{t}\right) d A_{t} \\
G_{1}^{\prime}+G_{2}^{\prime}=C E\left(Y_{t}\right)
\end{gathered}
$$

where

$$
\lambda=\frac{Y_{t, a}}{\left[N_{t, a}\right]^{1-\alpha}}
$$

and $\phi\left\{Y_{t}\right\}$ is from Equation 11. Solving the equation to get $N_{t, a}$ gives the solution for $Y_{t, a}$ also.

One characteristic of this equilibrium is that in case an economy follows a no-shock path for $A_{t}$, the household gets less than they could have gotten if they used the spot market. But their expected consumption remains certaintyequivalent, as should be.

\subsection{Collaterals}

The representative firm may instead ask for collaterals on the household, in the following way (completely state-contingent collaterals are not considered, though some degree of state contingency would be there): 
- The household provides "collaterals" for using a Fisherian futures market, and the firm returns them to the household whenever actual $A_{t}$ is greater than expected $A_{t}$. The firm returns only $L_{t}-\left(Y_{t, a}-\left[A_{t} N_{t, a}\right]^{1-\alpha}\right)$ out of collaterals, where $L_{t}$ is the amount of collaterals, if $A_{t}$ is lower than expected $A_{t}$ but with $Y_{t, a}<A_{t}\left[N_{t, a}\right]^{1-\alpha}+L_{t}$. The firm returns nothing on collaterals whenever $Y_{t, a} \geq A_{t}\left[N_{t, a}\right]^{1-\alpha}+L_{t}$.

To make expectations rationally consistent and have certainty equivalence properties for $Y_{t, a}$, the following condition is required for any Fisherian futures market at time $t^{\prime}$ with $t^{\prime}<t$ :

$$
\begin{gathered}
G_{1}=\int_{0}^{s}\left(Y_{t, a}-L_{t}\right) p\left(A_{t}\right) d A_{t} \\
G_{2}=\int_{s}^{s_{2}} A_{t}\left[N_{t, a}\right]^{1-\alpha} p\left(A_{t}\right) d A_{t} \\
G_{3}=\int_{s_{2}}^{\infty} \phi\left\{Y_{t}\right\} p\left(A_{t}\right) d A_{t} \\
G_{1}+G_{2}+G_{3}=s_{2}\left[N_{t, a}\right]^{1-\alpha}=Y_{t, a}
\end{gathered}
$$

where

$$
\begin{gathered}
s=\frac{E_{t^{\prime}}\left[A_{t}\right]\left(N_{t, a}\right)^{1-\alpha}-L_{t}}{\left[N_{t, a}\right]^{1-\alpha}} \\
s_{2}=E_{t^{\prime}}\left[A_{t}\right]
\end{gathered}
$$

and $\phi\left\{Y_{t}\right\}$ comes from Equation 11.

It is true that collaterals do not have to be set to satisfy certainty equivalence of $Y_{t, a}$, if consistent expectations are only desired. But from monetary/government authorities perspectives, if they have powers to control collaterals and their required amount, these properties may be desirable.

\subsection{Possible extensions}

For now, I have assumed that there is infinite cost in violating a contract. In practice, firms violate a contract and suffer from finite costs. This means that firms and agents play negotiation/renegotiation games.

Furthermore, relating to the same fields mentioned, $A_{t}$, in practice, is only partly observable for household agents, or "principals." This means that principalagent problems must be included as part of the model. All of these are the domains of several fields, such as mechanism design, game theory, industrial organization and so on. I will not discuss them for simplicity.

\section{Conclusion}

The presentation above shows how to introduce past-dependence of a real variable by introducing a Fisherian futures market and without introducing real and 
nominal frictions. While price is never introduced, it is nevertheless possible to introduce sluggish real variable changes.

Certainty equivalence problems of a Fisherian futures market have been presented, and the collaterals solution to the problems is presented.

Fisherian futures market models can also be used in sticky wage/labor context, where labor contracts are written before actual labor is supplied. 